\title{
The Teleost Retina as a Model for Developmental and Regeneration Biology
}

\author{
PETER F. HITCHCOCK ${ }^{1,2}$ and PAMELA A. RAYMOND ${ }^{2}$
}

\begin{abstract}
Retinal development in teleosts can broadly be divided into three epochs. The first is the specification of cellular domains in the larval forebrain that give rise to the retinal primordia and undergo early morphogenetic movements. The second is the neurogenic events within the retina proper-proliferation, cell fate determination, and pattern formation-that establish neuronal identities and form retinal laminae and cellular mosaics. The third, which is unique to teleosts and occurs in the functioning eye, is stretching of the retina and persistent neurogenesis that allows the growth of the retina to keep pace with the growth of the eye and other tissues. The first two events are rapid, complete by about 3 days postfertilization in the zebrafish embryo. The third is life-long and accounts for the bulk of retinal growth and the vast majority of adult retinal neurons. In addition, but clearly related to the retina's developmental history, lesions that kill retinal neurons elicit robust neuronal regeneration that originates from cells intrinsic to the retina. This paper reviews recent studies of retinal development in teleosts, focusing on those that shed light on the genetic and molecular regulation of retinal specification and morphogenesis in the embryo, retinal neurogenesis in larvae and adults, and injury-induced neuronal regeneration.
\end{abstract}

\section{INTRODUCTION}

$\mathbf{T}$ eleost fish are an excellent model for studying the developmental biology of various organs and tissues. The contributive features of this vertebrate taxon are well known and include external fertilization, large numbers of spawn, transparent eggs and embryos, rapid development, and, in selected species, the opportunity for genetic analysis. Zebrafish, for example, progress from fertilized egg to fully formed embryo within a few hours and from embryo to independently-living juvenile within a few days. Further, for many teleost species, growth is life-long and in general results from the continual accretion of new cells generated by tissue-specific stem cells. Finally, and per- haps tied to continual stem cell-based growth, many tissues in teleosts have the ability to regenerate. In this review, we focus on the early and persistent growth of the neural retina in teleosts. We define and describe three stages of development. The first two, specifying the retinal primordia and the early neurogenic events, are shared by all vertebrate retinas, whereas the third stage, continual growth-associated neurogenesis, is unique to teleosts. Our goal is to review studies that reveal the underlying principles and molecular mechanisms that govern the formation and growth of the teleost retina. In addition, we review studies of retinal regeneration in teleosts, a phenomenon that reflects the presence of stem cells in the mature retina.

Departments of ${ }^{1}$ Ophthalmology and Visual Sciences and ${ }^{2}$ Cell and Developmental Biology, University of Michigan Medical School, Ann Arbor, Michigan.

Supported by R01 EY07060 and P31 EY07003 (PFH) and R01 EY04318 and P60 DK02572 (PAR). 


\section{SPECIFICATION AND MORPHOGENESIS OF THE RETINA-FROM ONE MORPHOGENETIC FIELD TO TWO EYES}

The bilateral eyes that develop in vertebrate embryos are derived from a morphogenetic field in the anterior neural plate. Detailed fate mapping and patterns of gene expression show that at the end of gastrulation in teleosts a single morphogenetic field of cells in the anteriormedial forebrain becomes specified to generate the retinas. ${ }^{1,2}$ Under the influence of signals from the ventral midline, the single eye field splits into two optic primordia that grow laterally toward the surface ectoderm (Fig. 1). The tissue derivatives of the bilateral optic primordia include the optic stalk, the neural retina, the retinal pigmented epithelium, and the iris and ciliary epithelia. ${ }^{3}$ Other structures in the eyes are derived from surface ectoderm or head mesenchyme (cornea, lens, ciliary body, sclera, choroid, extrinsic ocular muscles), under the influence of inductive signals from the optic primordiam.

The cells in the early eye field have equivalent developmental potential and are migratory; a single cell can give rise to progeny in both ipsilateral and contralateral retinas. In zebrafish (Danio rerio) embryos, the initial singleeye field corresponds precisely to a domain of cells that express the genes, odd-paired-like (opl, now called zic1, a zinc finger transcriptional regulator $)^{2}$ and the three members of the retinal homeobox ( $r x)$ gene family $(r \times 1, r \times 2$ and $r \times 3 ; 4,5$ Fig. 2). Shortly after these cells acquire their retinal identity, the eye field is divided into two bilateral domains as a result of secreted signals (in the Nodal and Hedgehog families) that originate from the ventral midline-the axial mesoderm and ventral neural axis. ${ }^{3}$ This subdivision of the eye field in teleost fish depends on the lateral displacement of the retinal precursors as a consequence of the anterior movement along the midline of cells destined to form the ventral diencephalon. ${ }^{2}$ In mutations that alter retinal morphogenesis, the spatial pattern of retinal precursor cells expressing opl (zic1) and the $r x$ genes is altered in a manner that predicts the form of the eye defect. For example, in zebrafish mutants in which Nodal signaling is disrupted (e.g., cyclops and one-eyed-pinhead)

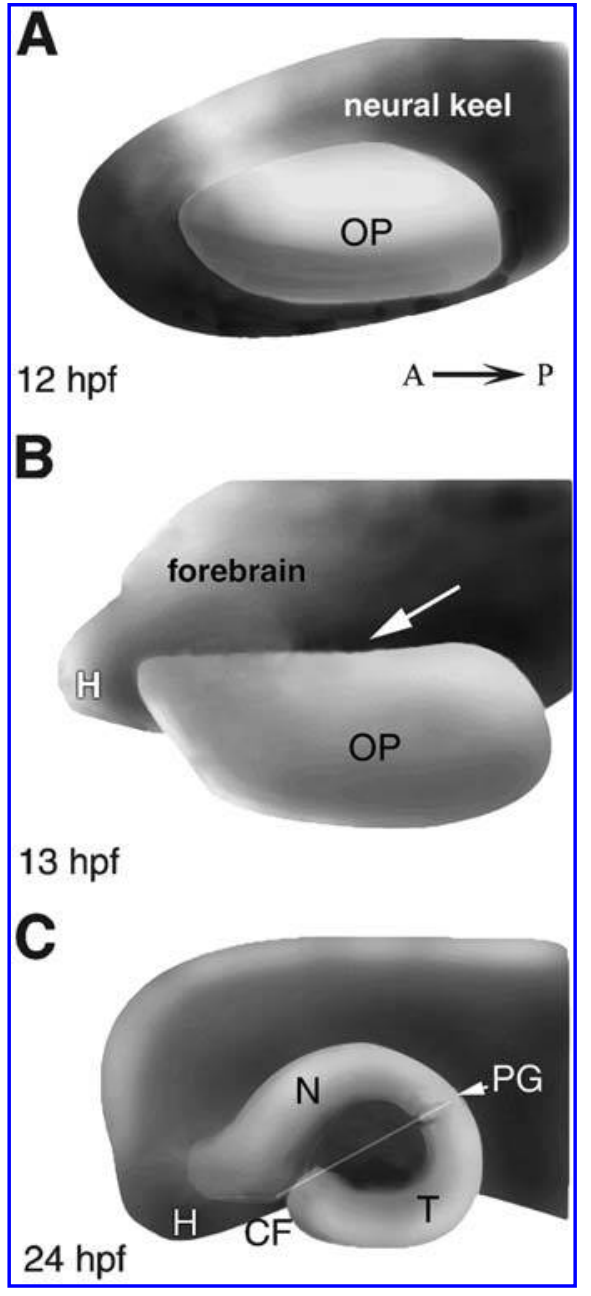

FIG. 1. Morphogenesis of the optic primordia in zebrafish. (A) The optic primordia (OP) arise from the anterior region of the neural keel at 12 hours postfertilization (hpf). (B) At $13 \mathrm{hpf}$, the optic primordia begin to separate from the neural keel at the posterior ends (white arrow), leaving the primordium attached by the optic stalk at the anterior end. A small protuberance at the anterior end of the neural keel is the hypothalamic primordium (H). (C) By 24 hpf, invagination of the lateral surface creates the optic cup. After ventral rotation of the anterior end of the neural keel, the optic stalks are located on the ventral side of the forebrain, adjacent to the hypothalamus $(\mathrm{H})$. The choroid fissure $(\mathrm{CF})$ is positioned near the anterior of the optic cup, opposite the posterior groove (PG). At later stages, the brain will rotate further ventrally so that choroid fissure and posterior groove will eventually align along the dorsoventral axis. The line between the choroid fissure and posterior groove subdivides the retina into nasal $(\mathrm{N})$ and temporal $(\mathrm{T})$ parts. Anterior is to the left and dorsal is up in all panels.

the eyes are fused across the ventral midline and sometimes form a single cyclopic eye. ${ }^{6}$ In these mutants, the precursor cells of the ventral diencephalon are not specified and fail 


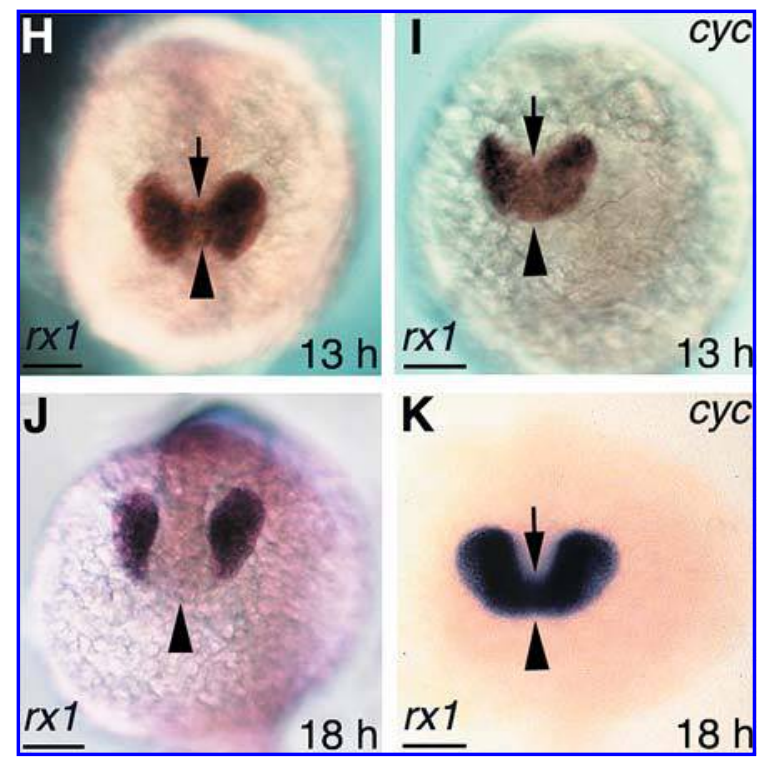

FIG. 2. The expression domain of $r x 1$ marks the eye field. $(\mathbf{H})-(\mathbf{K})$ The expression of $r x 1$ is compared in wild type $(\mathbf{H})$ and $(\mathbf{J})$ and cyclops zebrafish embryos $(\mathbf{I})$ and $(\mathbf{K})$ at 13 and 18 hours (h) postfertilization. Arrows indicate reduced expression of $r x 1$ at the caudal midline, which is associated with separation of the optic primordia. The arrowheads indicate the region in which $r x 1$ expression differs between wild type and cyclops embryos. Note that $r x 1$ is not expressed in the primordium of the hypothalamus in wild type embryos, as reflected by an indentation at the midline on the anterior side (arrowhead). In cyclops embryos (I) and (K), the rostral hypothalamus is missing, $r \times 1$ expression is not reduced at the anterior midline (arrowheads) and the two eyes are fused anteriorly across the midline. Scale bars: $100 \mu \mathrm{m}$. Reprinted with permission from Chuang and Raymond. ${ }^{5}$

to migrate anteriorly, and the cells expressing the opl(zic1) and $r x$ genes fail to separate along the midline. This phenotype can be recreated by ablating midline diencephalic precursors, demonstrating their importance in the process of bilateral cleavage of the eye field. ${ }^{2}$

Additional homeobox genes are essential for specifying the eye field in vertebrates., 3 In teleosts, members of the sine oculis (Six) gene family and the $R x$ genes appear to be the most directly involved in this process. Expression of six3 in zebrafish is first detected in the axial mesendoderm, and later in the anterior neurectoderm and head ectoderm. ${ }^{8,9}$ Overexpression of six 3 in zebrafish embryos results in expansion of the domain of $r \times 2$ and pax6 expression and enlargement of the forebrain and eyes. ${ }^{9,10}$ In medaka fish (Oryzias latipes) overexpression of Six3 has the additional effect of inducing ec- topic expression of Pax6 and $R \times 2$ and the formation of ectopic retinal primordia in the midbrain and cerebellum. ${ }^{11}$ In contrast, loss-offunction analysis of Six3 in medaka, with morpholino knock-down, results in the loss of forebrain and eyes. The Six3 protein functions as a transcriptional repressor and interacts with the co-repressor, Groucho, but its targets are not known. ${ }^{10}$ These studies suggest that Six3 is determinative for retina and is positioned near the apex of a regulatory genetic pathway that specifies retinal identity.

The $R x$ genes appear to play a specific role in specifying retinal identity and establishing the boundaries that separate the eye field from surrounding tissues. ${ }^{5}$ Overexpression of $r x 1$ or $r \times 2$ by mRNA injection in zebrafish embryos results in the expansion of the retinal field and a concomitant loss of telencephalon. ${ }^{5}$ Following injections of $r \times 2 \mathrm{mRNA}$, pigmented epithelium and neural retina differentiate in the rostral and dorsal forebrain (telencephalon). In these embryos, retinal tissues occasionally expand to the point where they meet at the midline, resulting in a single large eye fused dorsally in the region normally occupied by telencephalon. This phenotype is distinct from the ventral fusion of the eyes observed in $c y$ clops mutants as a consequence of defects in the ventral diencephalon. The expansion of neural retina at the expense of telencephalon in the $r \times 2$ gain-of-function experiments suggests that the ectopic expression of $r x$ genes results in the transformation of telencephalic precursors into retinal precursors, thereby shifting the boundary between these two tissue domains. Interestingly, in embryos injected with $r \times 2$ mRNA the frequency of eye mutations increases when one or more of the conserved domains within the $r x$ construct are deleted. ${ }^{5}$ This suggests that $r x$ gene expression is normally negatively regulated by proteins that interact with these conserved domains.

Following specification and bilateral separation, cells of the eye field undergo a proliferation-mediated evagination to form the optic primordia. A third member of the family of teleost $r x$ genes, $r x 3$, appears to serve as a molecular link between the initial specification of the eye field, its separation from the midline hypothalamic primordium, and the morpho- 
genesis of the optic primordia. The conditional, temperature-sensitive medaka mutant, eyeless $(\mathrm{el})$, lacks eyes as a result of an intronic insertion in the medaka $R x 3$ locus. A zebrafish mutant, chokh (chk), also fails to form eyes as a consequence of loss of function of $r \times 3 .{ }^{12,13}$ In these mutants, the optic primordia fail to evaginate, although the initial patterning of the forebrain is normal in that genes that specify the eye field (pax6, six3, rx1) are expressed, although $r \times 2$ is not. ${ }^{12-15}$ The inferred role of $r \times 3$ is to control morphogenesis of the nascent optic vesicle, perhaps regulating proliferation and/or survival of retinal progenitors. A downstream target of Rx3 is mab2112, a developmental regulator with unknown function, and morpholino knock-down of mab2112 partially phenocopies the $r \times 3$ (chk) mutation indicating that it is a critical effector of Rx3. ${ }^{13}$

Subsequent to evagination, the major cellular domains in the optic primordia appear to be established by members of the Hedgehog (Hh) family of signaling molecules, which are secreted by ventral midline cells. Two orthologues of the Drosophila Hh gene are expressed in the prechordal plate and adjacent ventral midline of the neural keel in zebrafish embryos: sonic hedgehog (shh) and twiggywinkle hedgehog (twhh). Overexpression of shh results in the failure of the eye field to separate at the midline and a reciprocal expansion of the optic stalks and reduction of neural retina. ${ }^{16}$ This result suggests that Shh secreted from the midline specifies the medial optic primordia as optic stalk, whereas tissues beyond the range of local Shh are specified as future pigmented epithelium and neural retina. The expansion of the optic stalks following overexpression of shh is thought to be complementary to the phenotype produced by defects in the nodal-related gene, cyclops, in which the absence of midline cells results in the absence of the optic stalks, which are replaced by pigmented epithelium and neural retina (see above).

In teleosts, the transition of optic primordia into ocular tissues has a unique morphogenetic basis $^{17,18}$ (Fig. 1). In most vertebrates, a spherical optic vesicle expands laterally from the wall of the diencephalon, attached to the optic stalk at its ventral border. Upon contact with the overlying ectoderm, the vesicle invaginates to form the roughly hemispheric optic cup, with the neural retina forming the inner layer and the retinal pigmented epithelium forming the outer. In teleosts, in contrast, the retinal primordia evaginate laterally and posteriorly from the forebrain as flattened, solid, wing-shaped structures that are attached to a rostrally positioned optic stalk. The cells in the optic primordia subsequently organize into two epithelial layers separated by a thin lumen, and the optic primorida are fused along their medial length to the neural tube. The primordia subsequently detach from the neural tube medially and rotate ventrally about a parasaggital axis, such that the original dorsal and ventral surfaces come to face laterally and medially, respectively (Fig. 1B). At this point, the optic stalks and slightly concave surface of the primordia have a spoon-shaped morphology. Next, due to the ventral flexure of the anterior neural tube and the consequent changes in orientation, the optic stalk and retinal primordia rotate again, but this time about a transverse axis through the forebrain, such that the stalks, previously positioned anteriorly, come to lie ventral to the retinal primordium (Fig. 1C). Following these movements, the lateral surface invaginates inward to create a hemispheric eyecup. The substantial changes in ocular shape that comprise these morphogenetic movements occur with negligible growth and an absence of cell proliferation. ${ }^{18}$ During this period considerable cell movement occurs in both layers of the eyecup, including involution of cells from the ventral outer layer of the eyecup (future pigmented epithelium) into the inner layer of neural retina. ${ }^{18,19}$

\section{NEUROGENESIS IN THE EMBRYONIC RETINA-SPREADING WAVES AND MAKING LAYERS}

Neurogenesis in the teleost retina is initiated in a small, discrete patch adjacent to the optic stalk in ventronasal retina (Fig. 3). Subsequent cellular differentiation then propagates away from this patch as a wave throughout the neuroepithelium. ${ }^{20-23}$ The first retinal progenitors to withdraw from the mitotic cycle [at $\sim 28$ hours postfertilization (hpf) in zebrafish] lie in a small cluster in the ganglion cell layer. ${ }^{22}$ This 


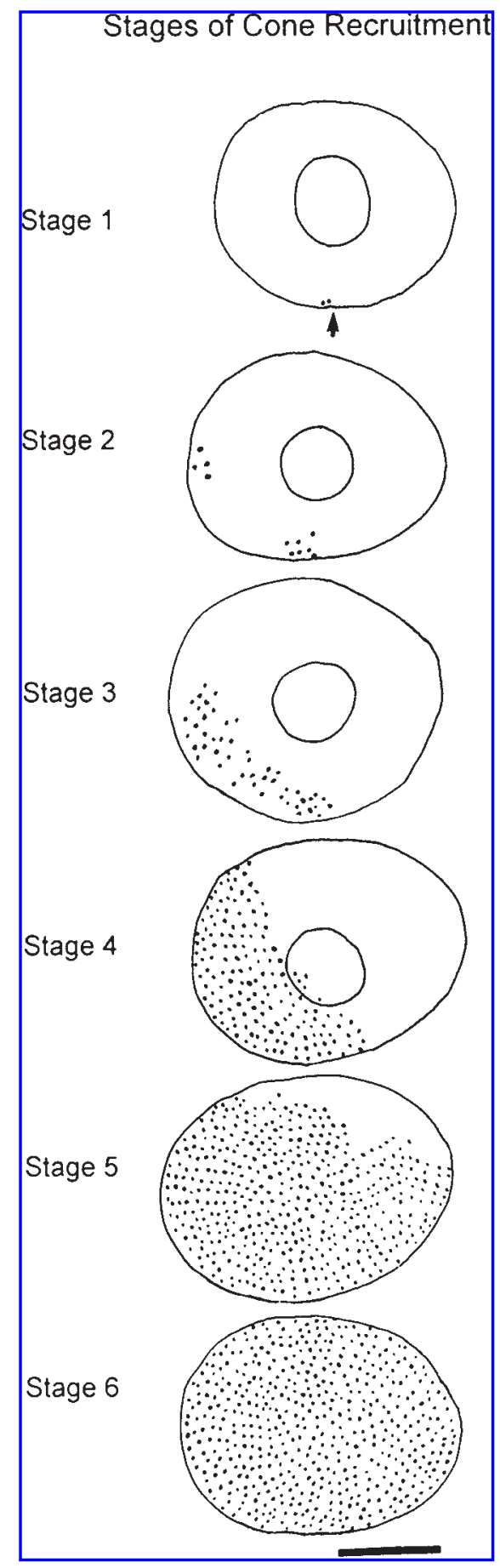

FIG. 3. Spatiotemporal pattern of retinal differentiation. Differentiation of cone photoreceptors is revealed by expression of cone opsin in whole mount preparations processed for in situ hybridization. These are composite drawings of whole eyes from zebrafish embryos ranging from 52 to 84 hours postfertilization, viewed from the back of the eye. Each dot represents an individual cone photoreceptor. These successive stages of cone recruitment illustrate the ventronasal to dorsotemporal gradient of retinal differentiation. The arrow indicates the position of the optic stalk. Dorsal is up and nasal is to the left. Scale bar:100 $\mu \mathrm{m}$. Reprinted with permission from Raymond et al. ${ }^{21}$ patch of postmitotic cells then expands in a circumferential wave within the ganglion cell layer, from ventronasal to dorsal to ventrotemporal retina. This wave, again originating in ventronasal retina, is then repeated in the inner nuclear layer, but with a delay of approximately 10 hours. After a second 10-hour delay, cells in the outer nuclear layer begin to withdraw from the mitotic cycle, although the moving circumferential wave of terminal birthdays is not as evident among the photoreceptors. The spatial pattern of cells withdrawing from the mitotic cycle is also revealed using a variety of markers of differentiated cells ${ }^{20,21,23-26}$ (Fig. 3). The pulsatile burst of neurogenesis and cellular maturation within each layer, originating within ventronasal retina and each separated by 10 hours, suggests that signals regulating this process must be sharply delimited both in time and space.

Two groups independently showed that shh (and twhh) are responsible for propagating the waves of neurogenesis through the developing zebrafish retina. Shh is initially expressed in the newly postmitotic ganglion cells within the precocious ventral patch and later in inner nuclear layer and overlying retinal pigmented epithelial (RPE) cells. The region of shh expression in the retina and RPE then enlarges in a spatial pattern that is coupled to the withdrawal of cells from the mitotic cycle, the acquisition of markers of differentiation and the formation of cellular laminae. ${ }^{26-28}$ The receptor for Hedgehog proteins, patched, is expressed by cycling retinal progenitors, demonstrating they are targets of Hedgehog function. ${ }^{27}$ Shh activates its own expression, ${ }^{26}$ and it is inferred that a repeated cycle of Shh signaling originating from newly differentiated neurons and influencing their mitotic neighbors sustains the neurogenic wave through the retina. Compromised Hedgehog signaling, either in the zebrafish mutants, sonic you, you-too, or slow muscle-omitted ${ }^{29-31}$ or by morpholino oligonucleotides targeted to shh and twhh, does not block the initial cellular differentiation in ventral retina, but does retard the wave of differentiation in the nuclear layers. ${ }^{26,27,32}$ The signals responsible for initiating retinal neurogenesis arise from the optic stalk ${ }^{33}$ and depend on Hh signals produced by the precordal plate at the ventral midline. ${ }^{32}$ 
An emergent spatial feature as neurogenesis is propagated through the laminae is the arrangement of neuron classes into two-dimensional mosaics. The best example of this is the planar arrangement of the different spectral types of cone photoreceptors. The cones in the adult zebrafish retina (as in many other teleost fish species) $)^{34,35}$ are arranged in a precise, twodimensional, mosaic pattern in the plane of the outer limiting membrane. Viewed en face (in a retinal flat mount or in tangential sections of retina), parallel rows of red and green double cone pairs alternate with rows of blue and UV single cones. ${ }^{21,36}$ Along each row of double cones, the orientation of the red/green pairs alternately reverses, blue and UV cones alternate along the rows of single cones, and the adjoining rows of single or double cones are out-ofphase, shifted by one half cycle. This produces another striking geometric feature of the cone mosaic pattern, its internal, reiterative, mirror image symmetry: in the direction orthogonal to the rows of single and double cones, cones are arranged in an invariant sequence such that UV cones are always flanked by green cones, and blue cones are always flanked by red cones. The regular arrangement of cones of each spectral type is apparent from the onset of opsin expression in the embryonic retina. ${ }^{20,21,25}$ The cones differentiate in the embryonic retina sequentially according to spectral type: red, then green, UV and blue, ${ }^{21}$ and differentiation commences in the ventronasal patch, as for all other retinal neurons, and proceeds in a curvilinear wave across the retina (Fig. 3).

From the above descriptions, it is obvious that neuronal differentiation and formation of the cellular laminae in the retina are intimately linked, and defects in cellular differentiation result in alterations in the formation of the retinal layers. However, the molecular mechanisms essential for the formation of nuclear layers and cellular mosaics can be separate from those mechanisms that control cellular differentiation. In zebrafish, four genetic loci that give rise to laminar defects without altering cellular differentiation have recently been cloned. (For a description of additional loci that give rise to patterning and other retinal defects, see Loosli et al., ${ }^{37}$ Pujic and Malicki, ${ }^{38}$ Tsujikawa and Malicki. ${ }^{39}$ ) The zebrafish mutant heart and soul (has) encodes an atypical protein kinase $\mathrm{C}$, nagie oko (nok) encodes a MAGUK-family scaffolding factor, glass onion (parachute)_glo(pac)_encodes zebrafish N-cadherin and mosaic eyes (moe) encodes a novel FERM domain-containing protein. ${ }^{40-45}$ In has mutants, the loss of this protein kinase $C$ activity affects the formation and maintenance of zonula adherens junctions, and its absence results in the disruption of cellular polarity in epithelial sheets throughout the embryo. In the retina the adherens junctions form but are lost at the onset of cellular differentiation, and this results in disruption of the nuclear layers, patchy loss of cells in the pigmented epithelium, and, interestingly, alterations in the relative orientations of mitotic spindles in dividing cells. ${ }^{40,41}$ In the retina, the membrane-associated guanylate kinase (MAGUK) scaffolding protein Nok is localized to junctional complexes. The loss-of-function mutation in the nok gene results in ectopic location of mitotic cells and the failure of retinal layering. ${ }^{42}$ Loss of the $\mathrm{Ca}^{+2}$-dependent cell adhesion molecule $\mathrm{N}$-cadherin also results in profound lamination defects without loss of cell-type specification. ${ }^{43,44,46,47}$ Finally, loss of the FERM (for 4.1 protein, ezrin, radixin, moesin) domain-containing protein results in absence of tight junctions between cells in the pigmented epithelium. This, in turn, results in patchy pigmented epithelium, ectopic mitoses within the retina and severe lamination defects. This mutation reveals that signaling from the pigmented epithelium to the retina is also required to establish normal cellular patterns within the retina. The MAGUK, N-cadherin and FERM proteins function in a non cell-autonomous manner. Together these studies reveal that basic patterning in the retina is dependent upon cell-cell interactions that establish or maintain cellular polarity within the retinal neuroepithelium and pigmented epithelium and that these mechanisms function independently of the mechanisms that specify cell fates or control cellular differentiation.

\section{RETINAL GROWTH FROM HATCHING AND ADULTHOOD-STEM CELLS AND PERSISTENT NEUROGENESIS}

The molecular mechanisms that govern early retinal development in teleosts have been examined only recently. In contrast, the growth of 
the retina in postlarval and adult fish retina has been actively studied for over 50 years. The origin of this field is traceable to a study of retinal development in the guppy, Lebistes reticulates, ${ }^{48}$ and was spawned by the observation that hatchling fish are visually active, but that the retina grows enormously from hatching to adulthood. This observation led to many interesting questions and two competing hypotheses regarding retinal growth that could be tested quantitatively: cell constancy with growth (no change in the number of retinal cells and progressive cellular spread) and cell addition with growth (retinal cells added continually to the extant retina). Although simple inspection shows that the teleost retina grows significantly by expansion and cells do spread apart, the inference from counting cells in retinas at different ages was unambiguous: new neurons are added to the teleost retina throughout an animal's life. ${ }^{34,48,49}$ This neuronal addition takes two forms. All neurons, with the exception of rod photoreceptors, are added appositionally from an annulus of neuroepithelial cells, known as the circumferential germinal (or marginal) zone (CGZ), that resides at the junction of the retina and iris (Fig. 4). The CGZ is a remnant of the original retinal neuroepithelium preserved at the retinal margin following cell differentiation and lamination centrally. This occurs early in development ( $\sim 48 \mathrm{hpf}$ in zebrafish), when the retina is a tiny fraction of its adult size, ${ }^{50}$ indicating that the vast majority of retinal neurons in an adult fish (e.g., encompassing 95\% of the retinal surface area in a two-year-old goldfish, Carassius auratus) are generated through mitotic activity in the CGZ at the retinal margin. ${ }^{51}$ Early investigators recognized the CGZ and correctly speculated on its role based on the elongated shape of its cells and their basophilia (characteristic of neuronal progenitors) and the presence of mitotic figures (e.g., Lyall ${ }^{34}$ ). Subsequent studies using ${ }^{3} \mathrm{H}$-thymidine to permanently label dividing cells in goldfish confirmed this inference. ${ }^{52-54}$ Because of the appositional accumulation of neurons generated from the circumferential germinal zone, there is spatial recapitulation of developmental time at the retinal margin, and all stages of development can be visualized in a single preparation. ${ }^{48,55}$ For example, each new cohort of cones is born along a circular, two-dimensional front at the CGZ, and along this front, cones differentiate sequentially, ${ }^{56}$ in the same order as in the embryonic retina. ${ }^{21,25}$

Although the dogma that the mature mammalian brain is a postmitotic organ has been shattered recently, one can point to the early studies of the teleost retina for evidence of multipotent neuronal progenitor cells (neural stem cells) in the adult vertebrate central nervous system. ${ }^{57}$ The teleost retina contains multipotent retinal progenitor cells that perpetually self renew, continuously generate neurons and, when existing neurons are destroyed, can regenerate all retinal cell types (see next section). These characteristics are the hallmarks of adult stem cells. ${ }^{58}$ The identity of the retinal stem cells, particularly those responsible for retinal regeneration, has been elusive. Analysis of gene expression in the retina of the frog, Xenopus laevis, indicates that multipotent retinal progenitor cells (stem cells) reside at the peripheral-most edge of the marginal germinal zone, immediately adjacent to the iris. ${ }^{55} \mathrm{An}$ equivalent analysis in zebrafish (Raymond, Barthel and Perkowski, unpublished observations) indicates that retinal stem cells in the teleost CGZ occupy a similar location (Fig. 4).

Rod photoreceptors, in contrast to cones and all other retinal neurons, are added interstitially throughout the differentiated retina from scattered, embedded, mitotic progenitor cells (rod precursors) that normally produce this single cell type. ${ }^{59-61}$ The retinal stem cells that sustain interstitial rod genesis, and potentially are responsible for injury-induced retinal regeneration (see below), are thought to reside in the inner nuclear layer of the differentiated retina, not the CGZ. Following cellular differentiation and formation of retinal laminae (see above section), the outer nuclear layer of the larval retina largely contains cone photoreceptors, and rods have yet to form (with the exception of the area of the precocious patch adjacent to the optic stalk) 20,21,36,62 All other rods are added in a secondary phase of neurogenesis, which arises from cells that both proliferate and migrate from the inner to outer nuclear layers. ${ }^{54,60,63}$ Upon arrival in the outer nuclear layer these cells, known as rod precursors, divide rapidly but for a limited number of cell divisions, and then differentiate into rod photoreceptors. 


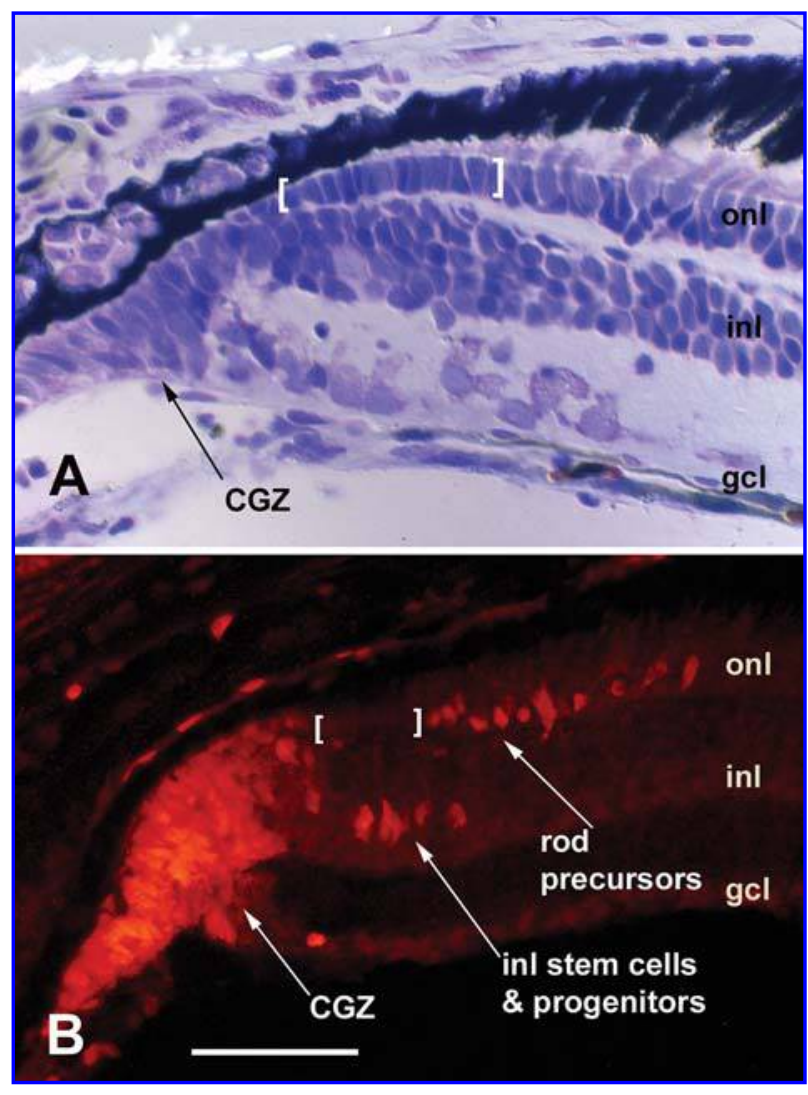

FIG. 4. Histological sections through the marginal retina of juvenile goldfish. The circumferential germinal zone (CGZ, panel A) contains retinal stem cells and progenitors that give rise to all cell types, with the exception of rod photoreceptors. The retina adjacent to the CGZ is larval-like in that only cone photoreceptors are present within the outer nuclear layer (brackets in A and B). Rod precursors and photoreceptor nuclei first appear in the more central, 'mature' retina. Panel B illustrates a section immunostained with antibodies against proliferating cell nuclear antigen, which labels mitotically-active cells within the CGZ and cells of the rod lineage within the inner and outer nuclear layers. onl - outer nuclear layer; inl - inner nuclear layer; gcl - ganglion cell layer. Scale bar: $50 \mu \mathrm{m}$.

Recent studies have shown that the larval pattern of proliferation and migration of cells from inner to outer retina is maintained into adulthood. In rainbow trout (Onchorynchus mykiss), in which the retinal growth and rod genesis are rapid, mitotically-active cells in the inner nuclear layer are very abundant and their migration to the outer nuclear layer is easily observed using markers of dividing cells. ${ }^{64,65}$ A similar pattern is revealed in the slow-growing adult goldfish by marking the more slowly dividing cells through prolonged systemic labeling with bromodeoxyuridine, BrdU. ${ }^{66} \mathrm{~A}$ careful examination of these cumulatively la- beled retinas revealed two types of proliferative cells in the inner nuclear layer: a relatively abundant population of cells with an elongated shape and a rare population of spherical cells. Comparison of the relative proportions of the BrdU-labeled cells over time showed that the epithelial-like cells migrate to the outer nuclear layer, whereas the spherical cells do not. Further, only spherical cells express the developmental regulatory gene, pax6. Based on these observations it was proposed that from the larval stage onward rods are generated throughout the retina from a three-cell lineage: rare, slowly-dividing and stationary stem cells in the inner nuclear layer give rise to rapidly-dividing progenitors that migrate from inner to outer nuclear layers, where they are recognized as rod precursors, the immediate neuronal precursors that differentiate into rod photoreceptors (Fig. 5). This lineage is based on models of the hematopoiesis, and may be generally applicable to all tissues that grow, have significant cellular turn-over, or can regenerate.

The migratory progenitors in the inner nuclear layer and rod precursors in the outer nuclear layer do not express pax6, but they do express the bHLH transcription factor neuroD in goldfish ${ }^{67}$ and zebrafish (M. Ochocinska and P. Hitchcock, unpublished observations), which is taken as evidence for a restriction in their cell fates to a pathway that generates rod photoreceptors only. Cells of the rod lineage are more mitotically active near the germinal zone, where the retina is less mature (Fig. 4), but they are present throughout the adult retina. From these studies a consensus model of persistent rod genesis in the retina was proposed. ${ }^{66,68}$ During early retinal differentiation, multipotent retinal progenitors (stem cells) generated in the embryonic neuroepithelium are retained among the differentiated neurons in the inner nuclear layer. These cells, which express pax6, divide slowly and asymmetrically, and give rise to another stem cell and a daughter that continues to divide and migrates from the inner nuclear to outer nuclear layers. Rod precursors in the outer nuclear layer divide a limited number of times and differentiate into rod photoreceptors. Rod genesis in the central-most retina is sustained thereafter by the progeny of these original stem cells. When differentiation restricts retinal neu- 


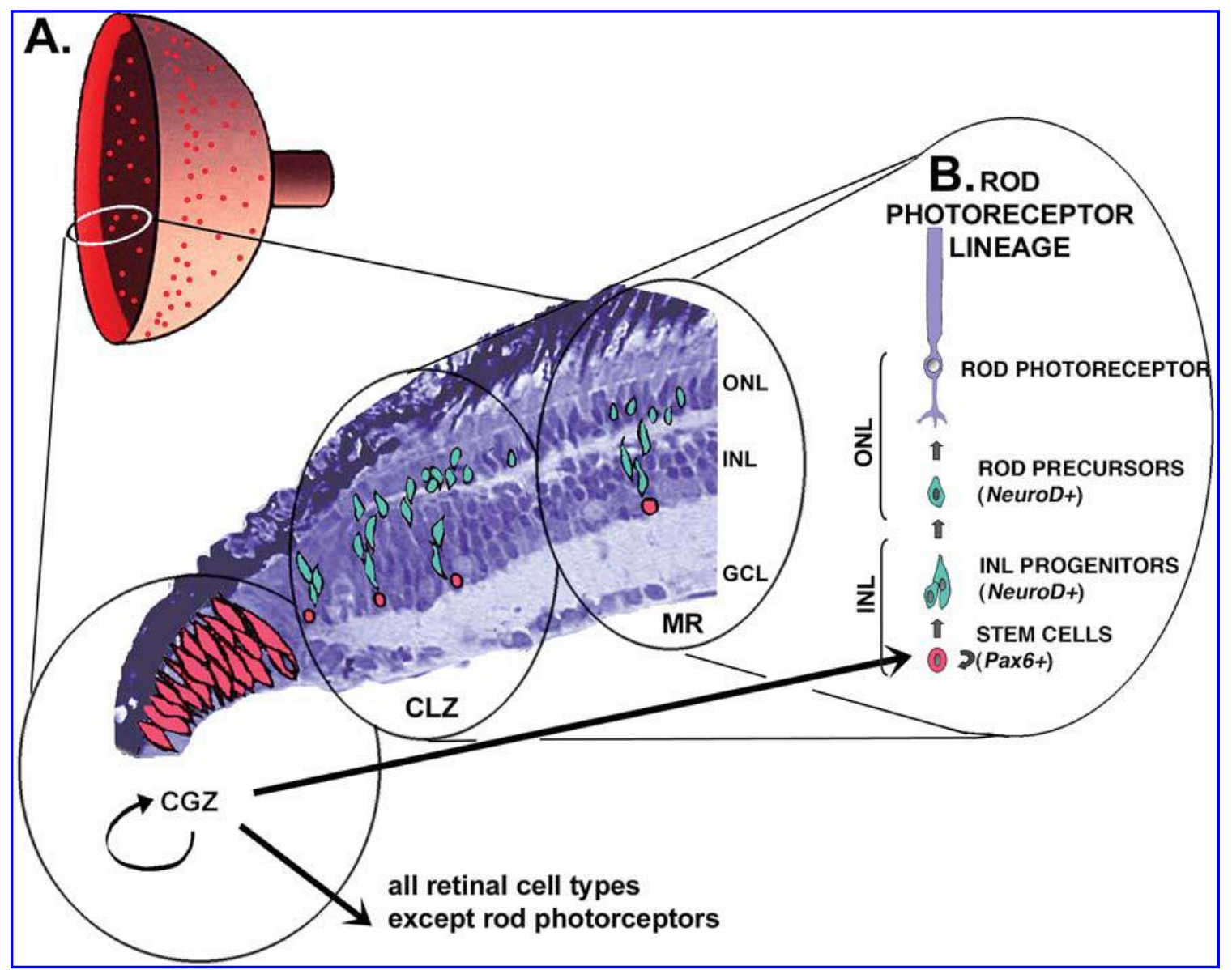

FIG. 5. Model of neurogenesis in the teleost retina. (A) cartoon of the teleost retina. The red annulus represent the circumferential germinal zone (CGZ) and the red dots represent cells of the rod lineage distributed throughout the mature retina. (B) rod photoreceptor lineage. Red cells express the homeobox transcription factor gene, pax6, whereas the green cells express the bHLH transcription factor, neuroD. Adapted from Otteson et al. ${ }^{66}$

rogenesis to the CGZ at the retinal margin, residual stem cells continue to be "seeded" into the inner nuclear layer of each newly added annulus of retina, thereby insuring that each new cohort of retinal neurons generated at the margin is provided with proliferating progenitor cells to supply its complement of rod photoreceptors from that point forward (Fig. 5).

Generating the correct number of cells during development and sustaining the correct number in adulthood is a requisite function of all organs, from blood to brain. Teleosts are unique among vertebrates in that growth is indeterminate; if they are adequately nourished, live in favorable environmental conditions and avoid predation, they will continue to grow as adults. ${ }^{69}$ Further, this growth is highly plastic and responsive to changes in nutrition and the environment. It is not surprising, therefore, that the growth hormone-insulin-like growth factor-1 axis, which regulates growth in all vertebrates, also governs growth-associated, persistent neurogenesis in the teleost retina. Growth hormone $(\mathrm{GH})$ functions in part by regulating the synthesis of insulin-like growth factor-1 (IGF-1) in target tissues. ${ }^{70,71}$ IGF-1, in turn, acts via endocrine and local autocrine/paracrine mechanisms, activating intracellular signaling events by binding to its cognate receptor, IGFR. Components of the GH signaling pathway, IGF-1, the IGFR and the GH receptor, are expressed in the teleost retina (Otteson et al., ${ }^{72} \mathrm{P}$. Hitchcock, unpublished observations). In vitro, IGF-1 stimulates proliferation of retinal progenitors in the CGZ and rod precursors in the outer nuclear layer. ${ }^{73,74}$ In addition, the retina 
is a target tissue for GH. Exogenous GH elevates IGF-1 message in the retina (and brain and liver) and stimulates dose-dependent proliferation of retinal progenitors in the CGZ and cells of the rod lineage.

In the retina, IGF-1 appears to serve as an intermediary molecule in a signaling network that regulates the growth-associated neurogenesis. IGF-1 is unlikely to be the only mitogenic peptide functioning in the teleost retina, however. For example, intraocular injection of either basic fibroblast growth factor or ciliary neurotrophic factor stimulate proliferation of cells within the inner nuclear layer. ${ }^{65,75}$ This suggests that different mitogenic peptides may act by more proximate mechanisms, perhaps mediating local neurogenic events, whereas the GH/IGF-1 axis serves as an overarching mechanism to regulate growth-associated neurogenesis in a manner that integrates the more proximal signals, intrinsic genetic programs, the nutritional status of the animal and environmental cues.

\section{INJURY-INDUCED NEUROGENESIS- ROBUST REPAIR FROM A YET-TO-BE IDENTIFIED CELLULAR SOURCE}

In the mature teleost retina, any insult that significantly depletes neurons stimulates robust neuronal regeneration and complete restoration of all cell types. The cellular source of regenerated retina is intrinsic to the retina, ${ }^{76,77}$ providing the strongest empirical evidence that stem cells are present in this tissue. Within a few days following a pharmacological lesion with the metabolic poison ouabain at a dose that largely destroys the neural retina in adult goldfish, radial clusters of mitotic cells appear across the retina, and from these neurogenic clusters neurons are regenerated. ${ }^{78,79}$ The latter study pointed to rod precursors as the most likely intrinsic cellular source of regenerated retina based on the following observations. First, while destroying virtually all neurons, ouabain does not destroy rod precursors, and second, regeneration is initiated only if neuronal death includes the outer nuclear layer. The conclusion that rod precursors are the cellular source of regenerated retina fits well with these experimental observations and with what was known at the time regarding rod genesis. More recent data, however, indicate that the cells that give rise to regenerated neurons originate within the inner nuclear layer. Selective destruction of photoreceptors, either using an ophthalmic laser or constant, bright illumination, ${ }^{80-83}$ leads to selective photoreceptor regeneration. In this instance, where the neural retina remains largely intact, injury-induced mitotic activity first appears in the inner nuclear layer. These proliferative cells then migrate to the outer nuclear layer, where they continue to divide and differentiate into cone photoreceptors. ${ }^{81}$ Rods, strictly speaking, cannot be said to regenerate, as they are constantly being produced in the intact, undamaged retina. As during normal development, rods are produced last, only after the regenerated neurons become postmitotic ${ }^{84}$ and through the mechanism of the rod lineage.

It seems intuitive to infer that the pax6-expressing stem cells in the inner nuclear layer are the source of regenerated neurons. This inference is consistent with the demonstration in the rodent retina that $P a x 6$ function is required to maintain the multipotent state of retinal progenitors. ${ }^{85}$ However, there are no data directly demonstrating the identity of the putative stem cells in retinal regeneration in the teleost retina. Additionally, some data implicate Müller glia as a possible source of regenerated neurons. Because differentiated Müller glia can re-enter the cell cycle, and they derive from the same lineage as retinal neurons, the question arises as to how stable is their glial identity and could they be a source of retinal stem cells? This question has become especially pertinent in the last few years, since neuronal progenitors in the embryonic nervous system and neural stem cells in the adult mammalian brain have now been identified, and to the astonishment of most researchers, neural stem cells are, in fact, radial glia and/or specialized astrocytes. ${ }^{86-88}$ In the mammalian cerebral cortex, for example, Pax6 expressed in radial glia gives them neurogenic potential. ${ }^{89}$ Müller glia in the retina have many of the same morphological and molecular properties as radial glia, including bipolar processes that span the width of the neuroepithelium, glycogen granules, the intermediate filament GFAP (glial fibrillary 
acidic protein), and expression of Notch1. ${ }^{88,90}$ Following laser-mediated (photocoagulation) destruction of photoreceptors in adult goldfish retina, Müller glia in the area of the lesion migrate to the outer nuclear layer, coincident with the regeneration of cone photoreceptors. ${ }^{81}$ These data further showed that reactive Müller glia proliferated and dedifferentiated coincident with production of regenerated cone photoreceptors, raising the possibility that the progeny of Müller glia might differentiate into neurons. Neurotoxic damage or intraocular injection of the growth factors FGF2 with IGF-1 in the chick retina also causes Müller glia to dedifferentiate, proliferate and co-express Pax6 and Chx10; while most of the progeny remain undifferentiated a few transiently express neurofilament protein or other neuronal markers. ${ }^{91}$ While the latter studies do not demonstrate replacement of retinal neurons, they do highlight the phenotypic plasticity of Müller glia.

Surprisingly, cone photoreceptors are the only retinal neuron that can be selectively regenerated. Ablation of specific cell types in inner retina ${ }^{92,93}$ or complete destruction of the inner layers with sparing of photoreceptors ${ }^{79}$ does not elicit regeneration. However, selective death of cones results in their selective regeneration (see above), and in some teleosts cone death and regeneration appears to be part of the retina's natural history. Coincident with juvenile metamorphosis and migration of salmonids from fresh water to marine environments, ultraviolet (UV) cones die by apoptosis. ${ }^{94,95}$ Upon returning from the sea UV cones can again be found in the retinas of sexually mature salmon captured in their natal streams. ${ }^{96}$ This loss and replacement of cone photoreceptors can be mimicked in laboratoryreared animals by manipulating plasma levels of thyroxine hormone. ${ }^{95,97}$ Cone death, however, is not required to elicit cone regeneration. If the retina is deformed to the point that gaps appear in the cone mosaic, new cones are generated and inserted into the gaps. ${ }^{98}$ These results suggest either that cone photoreceptors have unique standing among retinal neurons, perhaps reflecting conservation of mechanisms that evolved in salmonids, or the molecular mechanisms that initiate regeneration lie within the outer nuclear layer.
The laminar architecture and synaptic connectivity in the regenerated neural retina is nearly normal. ${ }^{99}$ The most obvious structural defect of the regenerated retina is in the less regular planar organization of the various cellular mosaics. This is most apparent for cones. Although cone photoreceptors are replaced, including all spectral cone types, the precise geometric organization of the cone mosaic array is not restored in the regenerated retina. ${ }^{82,100,101}$ Following loss of neurons, the retinal stem cells are triggered by injury to generate multiple, separate foci of proliferating, multipotent retinal progenitors, and thus the precise spatiotemporal pattern imposed by the wave of differentiation in the embryonic retina and the later appositional addition of neurons from the CGZ is not recapitulated. This observation provides strong support for the hypothesis that precise spatiotemporal coordination of production and differentiation of cones is a critical component of the unknown processes that regulate cone spectral cell fate choices and that pattern the cone mosaic arrays. ${ }^{102}$

Irrespective of the cellular origins of regenerated retina, regenerative mechanisms appear to be engaged in a manner that partially recapitulates retinal ontogeny. As mentioned above, following the loss of photoreceptors, cones and rods are generated in an order that recreates that observed in the embryonic retina. However, in the absence of a coordinated spatiotemporal moving front of differentiation, the precise planar array of the cone mosaic is not restored. Further, numerous developmental regulatory genes demonstrated to be key to normal embryonic retinal development (see above) are re-expressed by the injury-induced progenitors (Vsx1, Levine et al.;103 pax6, Hitchcock et al.;104 Notch 3, Sullivan et al.;105 N-cadherin, $\mathrm{Wu}$ et al. ${ }^{81}$ ). These observations can be taken as evidence that many, but not all, of the cellular mechanisms that govern embryonic and postlarval neurogenesis are re-engaged during regeneration.

\section{CONCLUSION}

The retina is a favored tissue for studying development of the nervous system. The adult 
retina is precisely laminated with a tight association between cell type and laminar address and within each layer neurons form cell type-specific mosaics. This structural precision enables investigators to reliably detect even subtle changes in cell fate specification and histogenesis that result from genetic alterations or experimental manipulations. Further, the evolutionary conservation of retinal structure and function is exquisite among vertebrates. Investigators chose to study embryonic retinal development using teleosts, since experimental manipulations are relatively easy and the mechanisms that govern formation of the vertebrate eye are conserved. The unique life history of teleosts also makes studying retinal growth in juvenile and adult animals equally informative. The retina keeps pace with lifelong growth of the eye and animal, in part, by the persistent accretion of neurons produced from resident stem cells. The function of neuronal stem cells in adult mammals is not completely understood. In contrast, neuronal stem cells in fish are required to mediate prolonged growth in these animals, from hatching to adulthood. Further, the capacity of teleosts to completely regenerate the neural retina and restore vision make it an attractive model to unravel mechanisms that allow some vertebrate brains to support neuronal regeneration. The rapid larval development, protracted neurogenesis and capacity for repair make the teleost retina an instructive model. The lessons learned from fish should provide insights into the principles that govern development and (potential) repair in all parts of the nervous system in a variety of species, including humans.

\section{ACKNOWLEDGMENTS}

The authors thank Jui Chang Chuang and Yushan Wang for the schematic drawing in Figure 1. Pamela Raymond has published previously as PR Johns.

\section{REFERENCES}

1. Woo K, Fraser SE. Order and coherence in the fate map of the zebrafish nervous system. Development 1995;121:2595-2609.
2. Varga ZM, Wegner J, Westerfield M. Anterior movement of ventral diencephalic precursors separates the primordial eye field in the neural plate and requires cyclops. Development 1999;126:5533-5546.

3. Chow RL, Lang RA. Early eye development in vertebrates. Annu Rev Cell Dev Biol 2001;17:255-296.

4. Chuang JC, Mathers PH, Raymond PA. Expression of three $R x$ homeobox genes in embryonic and adult zebrafish. Mech Dev 1999;84:195-198.

5. Chuang, J C, PA Raymond. Zebrafish genes rx1 and rx2 help define the region of forebrain that gives rise to retina. Dev Biol 2001;231:13-30.

6. Schier AF, Shen MM. Nodal signaling in vertebrate development. Nature 2000;403:385-389.

7. Chuang JC, Raymond PA. Embryonic origin of the eyes in teleost fish. Bioessays 2002;24:519-529.

8. Seo HC, Drivenes, Ellingsen S, Fjose A. Expression of two zebrafish homologues of the murine Six3 gene demarcates the initial eye primordia. Mech Dev 1998; 73:45-57.

9. Kobayashi M, Toyama R, Takeda H, Dawid IB, Kawakami K. Overexpression of the forebrain-specific homeo-box gene six3 induces rostral forebrain enlargement in zebrafish. Development 1998;125:29732982.

10. Kobayashi M, Nishikawa K, Suzuki T, Yamamoto M. The homeobox protein Six3 interacts with the Groucho corepressor and acts as a transcriptional repressor in eye and forebrain formation. Dev Biol 2001; 232:315-326.

11. Loosli F, Winkler S, Wittbrodt J. Six3 overexpression initiates the formation of ectopic retina. Genes Dev 1999;13:649-654.

12. Loosli F, Staub W, Finger-Baier KC, Ober EA, Verkade H, Wittbrodt J, Baier H. Loss of eyes in zebrafish caused by mutation of chokh/rx3. EMBO Rep 2003;4:894-899.

13. Kennedy BN, Stearns GW, Smyth VA, Ramamurthy V, van Eeden F, Ankoudinova I, Raible D, Hurley JB, Brockerhoff SE. Zebrafish $r x 3$ and mab21l2 are required during eye morphogenesis. Dev Biol 2004;270: 336-349.

14. Loosli F, Winkler S, Burgtorf C, Wurmbach E, Ansorge W, Henrich T, Grabher C, Arendt D, Carl M, Krone A, Grzebisz E, Wittbrodt J. Medaka eyeless is the key factor linking retinal determination and eye growth. Development 2001;128:4035-4044.

15. Winkler S, Loosli F, Henrich T, Wakamatsu Y, Wittbrodt J. The conditional medaka mutation eyeless uncouples patterning and morphogenesis of the eye. Development 2000;127:1911-1919.

16. Macdonald R, Barth KA, Xu Q, Holder N, Mikkola I, Wilson SW. Midline signaling is required for Pax gene regulation and patterning of the eyes. Development 1995;121:3267-3278.

17. Schmitt EA, Dowling JE. Early eye morphogenesis in the zebrafish, Brachydanio rerio. LComp Neurol 1994;344:532-542.

18. Li Z, Joseph NM, Easter SS Jr. The morphogenesis of the zebrafish eye, including a fate map of the optic vesicle. Dev Dyn 2000;218:175-188. 
19. Li Z, Hu M, Ochocinska MJ, Joseph NM, Easter SS Jr. Modulation of cell proliferation in the embryonic retina of zebrafish (Danio rerio). Dev Dyn 2000;219: 391-401.

20. Schmitt EA, Dowling JE. Comparison of topographical patterns of ganglion and photoreceptor cell differentiation in the retina of the zebrafish, Danio rerio. L Comp Neurol 1996;371:222-234.

21. Raymond PA, Barthel LK, Curran GA. Developmental patterning of rod and cone photoreceptors in embryonic zebrafish. L Comp Neurol 1995;359:537550.

22. Hu M, Easter SS. Retinal neurogenesis: the formation of the initial central patch of postmitotic cells. Dev Biol 1999;207:309-321.

23. Easter SS Jr, Malicki JJ. The zebrafish eye: developmental and genetic analysis. Results Probl Cell Differ 2002;40:346-370.

24. Burrill JD, Easter SS Jr. The first retinal axons and their microenvironment in zebrafish: cryptic pioneers and the pretract. LNeurosci 1995;15:2935-2947.

25. Stenkamp DL, Hisatomi O, Barthel LK, Tokunaga F, Raymond PA. Temporal expression of rod and cone opsins in embryonic goldfish retina predicts the spatial organization of the cone mosaic. Invest Ophthalmol Vis Sci 1996;37:363-376.

26. Neumann CJ, Nuesslein-Volhard C. Patterning of the zebrafish retina by a wave of sonic hedgehog activity. Science 2000;289:2137-2139.

27. Stenkamp DL, Frey RA, Prabhudesai SN, Raymond PA. Function for Hedgehog genes in zebrafish retinal development. Dev Biol 2000;220:238-252.

28. Shkumatava A, Fischer S, Muller F, Strahle U, Neumann CJ. Sonic hedgehog, secreted by amacrine cells, acts as a short-range signal to direct differentiation and lamination in the zebrafish retina. Development 2004;131:3849-3858.

29. Schauerte HE, van Eeden FJ, Fricke C, Odenthal J, Strahle U, Haffter P. Sonic hedgehog is not required for the induction of medial floor plate cells in the zebrafish. Development 1998;125:2983-2993.

30. Karlstrom RO, Talbot WS, Schier AF. Comparative synteny cloning of zebrafish you-too: mutations in the Hedgehog target gli2 affect ventral forebrain patterning. Genes Dev 1999;13:388-393.

31. Varga ZM, Amores A, Lewis KE, Yan YL, Postlethwait JH, Eisen JS, Westerfield M. Zebrafish smoothened functions in ventral neural tube specification and axon tract formation. Development 2001;128:3497-3509.

32. Stenkamp DL, Frey RA. Extraretinal and retinal hedgehog signaling sequentially regulate retinal differentiation in zebrafish. Dev Biol 2003;258:349-363.

33. Masai I, Stemple DL, Okamoto H, Wilson SW. Midline signals regulate retinal neurogenesis in zebrafish. Neuron 2000;27:251-263.

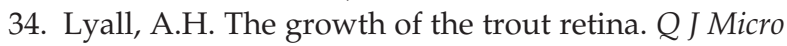
Sci 1957;98:101-110.

35. Nishiwaki Y, Oishi T, Tokunaga F, Morita T. Threedimensional reconstitution of cone arrangement on the spherical surface of the retina in the medaka eyes. Zool Sci 1997;14:795-801.
36. Branchek T, Bremiller R. The development of photoreceptors in the zebrafish, Brachydanio rerio. I. Structure. L Comp Neurol 1984;224:107-115.

37. Loosli F, Bene FD, Quiring R, Rembold M, MartinezMorales JR, Carl M, Grabher C, Iquel C, Krone A, Wittbrodt B, Winkler S, Sasado T, Morinaga C, Suwa H, Niwa K, Henrich T, Deguchi T, Hirose Y, Iwanami N, Kunimatsu S, Osakada M, Watanabe T, Yasuoka A, Yoda H, Winkler C, Elmasri $\mathrm{H}$, Kondoh $\mathrm{H}$, Furutani-Seiki M, Wittbrodt J. Mutations affecting retina development in Medaka. Mech Dev 2004;121: 703-714.

38. Pujic Z, Malicki J. Retinal pattern and the genetic basis of its formation in zebrafish. Semin Cell Dev Biol 2004;15:105-114.

39. Tsujikawa M, Malicki J. Intraflagellar transport genes are essential for differentiation and survival of vertebrate sensory neurons. Neuron 2004;42:703-716.

40. Horne-Badovinac S, Lin D, Waldron S, Schwarz M, Mbamalu G, Pawson T, Jan Y, Stainier DY, Abdelilah-Seyfried S. Positional cloning of heart and soul reveals multiple roles for PKC lambda in zebrafish organogenesis. Curr Biol 2001;11:1492-1502.

41. Peterson RT, Mably JD, Chen JN, Fishman MC. Convergence of distinct pathways to heart patterning revealed by the small molecule concentramide and the mutation heart-and-soul. Curr Biol 2001;11:14811491.

42. Wei X, Malicki J. nagie oko, encoding a MAGUK-family protein, is essential for cellular patterning of the retina. Nat Genet 2002;31:150-157.

43. Malicki J, Jo H, Pujic Z. Zebrafish N-cadherin, encoded by the glass onion locus, plays an essential role in retinal patterning. Dev Biol 2003;259:95-108.

44. Masai I, Lele Z, Yamaguchi M, Komori A, Nakata A, Nishiwaki Y, Wada H, Tanaka H, Nojima Y, Hammerschmidt M, Wilson SW, Okamoto H. N-cadherin mediates retinal lamination, maintenance of forebrain compartments and patterning of retinal neurites. Development 2003;130:2479-2494.

45. Jensen AM, Westerfield M. Zebrafish mosaic eyes is a novel FERM protein required for retinal lamination and retinal pigmented epithelial tight junction formation. Curr Biol 2004;14:711-717.

46. Pujic Z, Malicki J. Mutation of the zebrafish glass onion locus causes early cell-nonautonomous loss of neuroepithelial integrity followed by severe neuronal patterning defects in the retina. Dev Biol 2001; 234:454-469.

47. Erdmann B, Kirsch FP, Rathjen FG, More MI. N-cadherin is essential for retinal lamination in the zebrafish. Dev Dyn 2003;226:570-577.

48. Müller H. Bau und Wachstrum der Netzhaut des Guppy (Lebistes reticulatus). Zool Jahrb Abt Allg Zool 1952;63:275-324.

49. Johns PR, Easter SS Jr. Growth of the adult goldfish eye. II. Increase in retinal cell number. $L \mathrm{Comp} \mathrm{Neu-}$ rol 1977;176:331-341.

50. Marcus RC, Delaney CL, Easter SS Jr. Neurogenesis in the visual system of embryonic and adult zebrafish (Danio rerio). Vis Neurosci 1999;16:417-424. 
51. Raymond PA. Movement of retinal terminals in goldfish optic tectum predicted by analysis of neuronal proliferation. I Neurosci 1986;6:2479-2488.

52. Johns PR. Growth of the adult goldfish eye. III. Source of the new retinal cells. LComp Neurol 1977; 176:343-357.

53. Meyer RL. Evidence from thymidine labeling for continuing growth of retina and tectum in juvenile goldfish. Exp Neurol 1978;59:99-111.

54. Hagedorn M, Fernald RD. Retinal growth and cell addition during embryogenesis in the teleost, Haplochromis burtoni. L Comp Neurol 1992;321:193-208.

55. Perron M, Kanekar S, Vetter ML, Harris WA. The genetic sequence of retinal development in the ciliary margin of the Xenopus eye. Dev Biol 1998;199:185200.

56. Stenkamp DL, Barthel LK, Raymond PA. Spatiotemporal coordination of rod and cone photoreceptor differentiation in goldfish retina. I Comp Neurol 1997;382:272-284.

57. Raymond PA. Restoration of vision. In Handbook of Adult and Fetal Stem Cells, chapter 71. Elsevier Science, San Diego, CA; in press.

58. Alvarez-Buylla A, Temple S. Stem cells in the developing and adult nervous system. INeurobiol 1998; 36:105-110.

59. Johns PR, Fernald RD. Genesis of rods in teleost fish retina. Nature 1981;293:141-142.

60. Johns PR. Formation of photoreceptors in larval and adult goldfish. L Neurosci 1982;2:178-198.

61. Hagedorn M, Mack AF, Evans B, Fernald RD. The embryogenesis of rod photoreceptors in the teleost fish retina, Haplochromis burtoni. Brain Res Dev Brain Res 1998;108:217-227.

62. Kljavin IJ. Related Articles, Links Abstract Early development of photoreceptors in the ventral retina of the zebrafish embryo. LComp Neurol 1987;260:461-471.

63. Raymond PA, Rivlin PK. Germinal cells in the goldfish retina that produce rod photoreceptors. Dev Biol 1987;122:120-138.

64. Julian D, Ennis K, Korenbrot JI. Birth and fate of proliferative cells in the inner nuclear layer of the mature fish retina. L Comp Neurol 1998;394:271-282.

65. Faillace MP, Julian D, Korenbrot JI. Mitotic activation of proliferative cells in the inner nuclear layer of the mature fish retina: regulatory signals and molecular markers. I Comp Neurol 2002;451:127-141.

66. Otteson DC, D'Costa AR, Hitchcock PF. Putative stem cells and the lineage of rod photoreceptors in the mature retina of the goldfish. Dev Biol 2001;232: 62-76.

67. Hitchcock P, Kakuk-Atkins L. The basic helix-loophelix transcription factor neuroD is expressed in the rod lineage of the teleost retina. I Comp Neurol 2004; 477:108-117.

68. Otteson DC, Hitchcock PF. Stem cells in the teleost retina: persistent neurogenesis and injury-induced regeneration. Vision Res 2003;43:927-936.

69. Brown ME. The Physiology of Fishes, vol. 1. Metabolism. 1957. Academic Press, NY.
70. Butler AA, Le Roith D. Control of growth by the somatropic axis: growth hormone and the insulin-like growth factors have related and independent roles. Annu Rev Physiol 2001;63:141-164.

71. Duan C. Nutritional and developmental regulation of insulin-like growth factors in fish. L Nutr 1998; 128:306S-314S.

72. Otteson DC, Cirenza PF, Hitchcock PF. Persistent neurogenesis in the teleost retina: evidence for regulation by the growth-hormone/insulin-like growth factor-I axis. Mech Dev 2002;117:137-149.

73. Boucher SE, Hitchcock PF. Insulin-related growth factors stimulate proliferation of retinal progenitors in the goldfish. L Comp Neurol 1998;394:386-394.

74. Mack AF, Fernald RD. Regulation of cell division and rod differentiation in the teleost retina. $\underline{\text { Brain Res }}$ Dev Brain Res 1993;76:183-187.

75. Negishi K, Shinagawa S. Fibroblast growth factor induces proliferating cell nuclear antigen-immunoreactive cells in goldfish retina. Neurosci Res 1993;18: 143-156.

76. Raymond PA, Hitchcock PF. Retinal regeneration: common principles but a diversity of mechanisms. Adv Neurol 1997;72:171-184.

77. Raymond PA, Hitchcock PF. How the neural retina regenerates. Results Probl Cell Differ 2000;31:197-218.

78. Maier W, Wolburg H. Regeneration of the goldfish retina after exposure to different doses of ouabain. Cell Tissue Res 1979;202:99-118.

79. Raymond PA, Reifler MJ, Rivlin PK. Regeneration of goldfish retina: rod precursors are a likely source of regenerated cells. L Neurobiol 1988;19:431-463.

80. Vihtelic TS, Hyde DR. Light-induced rod and cone cell death and regeneration in the adult albino zebrafish (Danio rerio) retina. I Neurobiol 2000;44:289-307.

81. Wu DM, Schneiderman T, Burgett J, Gokhale P, Barthel L, Raymond PA. Cones regenerate from retinal stem cells sequestered in the inner nuclear layer of adult goldfish retina. Invest Ophthalmol Vis Sci 2001;42:2115-2124.

82. Braisted JE, Essman TF, Raymond PA. Selective regeneration of photoreceptors in goldfish retina. Development 1994;120:2409-2419.

83. Hitchcock PF, Lindsey Myhr KJ, Easter SS Jr, Mangione-Smith R, Jones DD. Local regeneration in the retina of the goldfish. L Neurobiol 1992;23:187-203.

84. Raymond PA. Retinal regeneration in teleost fish. Ciba Found Symp 1991;160:171-186.

85. Marquardt T, Ashery-Padan R, Andrejewski N, Scardigli R, Guillemot F, Gruss P. Pax6 is required for the multipotent state of retinal progenitor cells. Cell 2001;105:43-55.

86. Barres BA. A new role for glia: generation of neurons! Cell 1999;97:667-670.

87. Alvarez-Buylla A, Garcia-Verdugo JM, Tramontin AD. A unified hypothesis on the lineage of neural stem cells. Nat Rev Neurosci 2001;2:287-293.

88. Campbell K, Gotz M. Radial glia: multi-purpose cells for vertebrate brain development. Trends Neurosci 2002;25:235-238. 
89. Heins N, Malatesta P, Cecconi F, Nakafuku M, Tucker KL, Hack MA, Chapouton P, Barde YA, Gotz M. Glial cells generate neurons: the role of the transcription factor Pax6. Nat Neurosci 2002;5:308-315. Erratum in: Nat Neurosci 2002;5:500.

90. Chanas-Sacre G, Rogister B, Moonen G, Leprince P. Radial glia phenotype: origin, regulation, and transdifferentiation. J Neurosci Res 2000;61:357-363.

91. Fischer AJ, Reh TA. Potential of Müller glia to become neurogenic retinal progenitor cells. Glia 2003; 43:70-76.

92. Hitchcock PF. Exclusionary dendritic interactions in the retina of the goldfish. Development 1989;106:589 598.

93. Braisted JE, Raymond PA. Regeneration of dopaminergic neurons in goldfish retina. Development 1992; 114:913-919.

94. Kunz YW, Wildenburg G, Goodrich L, Callaghan E. The fate of ultraviolet receptors in the retina of the Atlantic salmon (Salmo salar). Vision Res 1994;341375341383.

95. Hawryshyn CW, Martens G, Allison WT, Anholt BR. Regeneration of ultraviolet-sensitive cones in the retinal cone mosaic of thyroxin-challenged post-juvenile rainbow trout (Oncorhynchus mykiss). L Exp Biol 2003;206:2665-2673.

96. Novales Flamarique I. The ontogeny of ultraviolet sensitivity, cone disappearance and regeneration in the sockeye salmon Oncorhynchus nerka. L Exp Biol 2000;203:1161-1172.

97. Browman HI, Hawryshyn CW. The developmental trajectory of ultraviolet photosensitivity in rainbow trout is altered by thyroxine. Vision Res 1994;34:1397-1406.

98. Cameron DA, Easter SS Jr. Cone photoreceptor regeneration in adult fish retina: phenotypic determination and mosaic pattern formation. L Neurosci 1995;15:2255-2271.

99. Hitchcock PF, Cirenza P. Synaptic organization of regenerated retina in the goldfish. L Comp Neurol 1994;343:609-616.
100. Cameron DA, Carney LH. Cell mosaic patterns in the native and regenerated inner retina of zebrafish: implications for retinal assembly. I Comp Neurol 2000;416:356-367.

101. Stenkamp DL, Cameron DA. Cellular pattern formation in the retina: retinal regeneration as a model system. Mol Vis 2002;8:280-293.

102. Raymond PA, Barthel LK. A moving wave patterns the cone photoreceptor mosaic array in the zebrafish retina. Int J Neurobiol 2004; in press.

103. Levine EM, Hitchcock PF, Glasgow E, Schechter N. Restricted expression of a new paired-class homeobox gene in normal and regenerating adult goldfish retina. I Comp Neurol 1994;348:596-606.

104. Hitchcock PF, Macdonald RE, VanDeRyt JT, Wilson SW. Antibodies against Pax6 immunostain amacrine and ganglion cells and neuronal progenitors, but not rod precursors, in the normal and regenerating retina of the goldfish. L Neurobiol 1996;29: 399-413.

105. Sullivan SA, Barthel LK, Largent BL, Raymond PA. A goldfish Notch-3 homologue is expressed in neurogenic regions of embryonic, adult, and regenerating brain and retina. Dev Genet 1997;20: 208-223.

Address reprint requests to: Peter F. Hitchcock Department of Ophthalmology and Visual Sciences University of Michigan Medical School W. K. Kellogg Eye Center 1000 Wall Street Ann Arbor, MI 48105

E-mail: peterh@med.umich.edu 



\section{This article has been cited by:}

1. Z. Qin, L. K. Barthel, P. A. Raymond. 2009. Genetic evidence for shared mechanisms of epimorphic regeneration in zebrafish. Proceedings of the National Academy of Sciences 106:23, 9310-9315. [CrossRef]

2. Anda-Alexandra Calinescu, Thomas S. Vihtelic, David R. Hyde, Peter F. Hitchcock. 2009. Cellular expression of Midkine-a and Midkine-b during retinal development and photoreceptor regeneration in zebrafish. The Journal of Comparative Neurology 514:1, 1-10. [CrossRef]

3. Chen Sok Lam, Martin März, Uwe Strähle. 2009. gfap and nestin reporter lines reveal characteristics of neural progenitors in the adult zebrafish brain. Developmental Dynamics 238:2, 475-486. [CrossRef]

4. Sean C. Kassen, Vijay Ramanan, Jacob E. Montgomery, Christopher T. Burket, Chang-Gong Liu, Thomas S. Vihtelic, David R. Hyde. 2007. Time course analysis of gene expression during light-induced photoreceptor cell death and regeneration in albino zebrafish. Developmental Neurobiology 67:8, 1009-1031. [CrossRef]

5. ALLEN F. MENSINGER, MAUREEN K. POWERS. 2007. Visual function in regenerating teleost retina following surgical lesioning. Visual Neuroscience 24:03. . [CrossRef]

6. Malgorzata J. Ochocinska, Peter F. Hitchcock. 2007. Dynamic expression of the basic helix-loop-helix transcription factor neuroD in the rod and cone photoreceptor lineages in the retina of the embryonic and larval zebrafish. The Journal of Comparative Neurology 501:1, 1-12. [CrossRef]

7. W. Ted Allison, Stephen G. Dann, Kathy M. Veldhoen, Craig W. Hawryshyn. 2007. Degeneration and regeneration of ultraviolet cone photoreceptors during development in rainbow trout. The Journal of Comparative Neurology 499:5, 702-715. [CrossRef]

8. W. TED ALLISON, TED E. HALLOWS, TRUDI JOHNSON, CRAIG W. HAWRYSHYN, DONALD M. ALLEN. 2006. Photic history modifies susceptibility to retinal damage in albino trout. Visual Neuroscience 23:01. . [CrossRef]

9. 2005. Recent Papers on Zebrafish and Other Aquarium Fish ModelsRecent Papers on Zebrafish and Other Aquarium Fish Models. Zebrafish 1:4, 369-375. [Citation] [PDF] [PDF Plus] 